Two problems in giving effect to such a policy are how to attract more clinicians into rheumatology and how to stimulate the interest of the pure scientist in the study of fundamental problems which may bear on rheumatism. Hope is expressed that work will soon begin on the difficult problems of what controls the behaviour of the fibroblast and what are the enzyme systems involved. Of four new grants in this field during the year, three have been given to centres already supported by the Foundation; the fourth, of $£ 4,000$ over two years, was to the Institute of Orthopædics for research on the constituents of cartilage. The controlled clinical trials of cortisone and allied hormones suggest that both prednisone and prednisolone are superior to cortisone in the treatment of rheumatoid arthritis and that there may be some fundamental difference between the action of these two steroids and cortisone. Of other grants for medical research may be mentioned one of $£ 80,000$ to endow a chair in child surgery at the University of London; up to $£ 2,000$ to the University of Leeds towards the cost of acquiring a Skeggs Leonard type of artificial kidney for comparison with the Merrill type; $£ 2,250$ a year for three years and a capital grant of $£ 300$ to the Institute of Neurology, University of London, for a long-term clinical investigation into the effects of hypotensive drugs and anticoagulant therapy in the treatment of cerebrovascular disease; a further grant of $£ 10,700$ over two years to the Tuberculous Meningitis Unit, United Oxford Hospitals, for research on disseminated sclerosis ; up to $£ 12,000$ towards the cost of adapta. tions to the Pioneer Health Centre, Peckham, for a diagnostic centre for local doctors; and $£ 2,520$ a year for three years to the Institute of Psychiatry, University of London, for work on cutting the pituitary stalk.

Among the grants for the care of old people and research in aging are one of $£ 2,500$ to the National
Institute for Adult Education for a comprehensive inquiry into existing educational facilities for the elderly, the use made of them, and the general role of adult education in helping people to adjust themselves to retirement and to continue leading an active life; $£ 3,000$ for a pilot study into the economic circumstances of people over retirement age; $£ 2,000$ over three years to the University of Exeter for an investigation into the effects of aging on the performance of tasks of varying complexity; and a further grant of a five-year fellowship rising from $£ 1,500$ to $£ 1,700$ a year to Dr. A. Comfort for his long-term investigations at University College, London, into the aging of fish and the pattern of aging in dogs and thoroughbred horses, which may yield information on the inheritance of longevity and the effects of parental age.

Other grants for social research and education during the year include: $\mathfrak{f} 6,850$ over three years in support of a study of the social composition of a Lancashire industrial town, which will comprise an analysis of the number and functions of the professional, managerial and administrative groups and their role in the life of the community, and a study of the working-class population and its part in political and associational life and the relation of local to national culture. This study is being conducted by the Department of Social Anthropology and Sociology, University of Manchester.

A brief summary is given of the first part of $\mathbf{M r}$. J. Trenaman's study of the educational possibilities of radio and television, newspapers and films, towards which a further grant of $£ 500$ has been made. Broadcasting and the Press are the only contemporary influences that can reach across a majority of the population to the fringes of the 45 per cent that are resistant to education in its broader sense, and $\mathrm{Mr}$. Trenaman thinks they could do more to stimulate critical thinking.

\title{
SCIENTIFIC BASIS OF LAND PLANNING IN THE TROPICS
}

\begin{abstract}
$\mathrm{A}^{\mathrm{x}}$ $\mathrm{N}$ inescapable problem of the present-day world is the increasing pressure of population on land resources. Widespread knowledge and practice of death eontrol have overtaken birth control so that, one by one, the countries of the world are experiencing the problem of how to match expanding population with expanding food production. The problem has now hit the Gambia, and in facing it the Gambian Government, perhaps influenced by the salutary lesson of the failure of the poultry scheme, is wisely realizing the fundamental need for a basis of factual knowledge on which to plan its land use and land planning policy. Rather more than a hundred and fifty years ago Britain, faced with the imminent possibility of a Napoleonic invasion, realized the need for adequate maps and set up the Ordnance Survey.

To-day, the far-flung parts of the Commonwealth face crises of many different types, and the Directorate of Overseas Surveys has been charged with the Herculean task of providing at least a skeleton map cover as a basis of operations. The maps the Directorate is producing are for the most part on a scale of $I: 50,000$ and are based essentially on air
\end{abstract}

photographs. At the same time, the air photographic cover provides a wealth of other information, notably that of present land use. There are special reasons for using this information to prepare a series of land use maps* of the Gambia on the scale of $1: 25,000$. The sandy Ieached soils in the past have been worked on a system of bush fallowing but produce only indifferent crops of sorghum, millet with some cassava and maize and groundnuts as a cash crop, and a little upland rice. With increased population the period of fallow is so shortened that the soils do not recover and the system breaks down. With Government aid, attention has been turned to the clearance of mangrove and grass swamps bordering the Gambia River and the cultivation of their heavy clay soils for rice. This is more revolutionary than it sounds, because, traditionally, the women have cultivated the land; but swamp clearance, construction of bunds and causeways and mechanized

* Directorate of Overseas Surveys. Gambia Land Use Map, Sheet 12/1 : Janneh Kunda. Gambia Land Use Map, Sheet 14/11 : Mansa Konko. (Scale 1:25,000.) (Tolworth: Directorate of Overseas Surveys, 1958. Obtainable from Edward Stanford, Ltd., 12 Long Acre, London, 
ploughing are man's work. The policy has apparently been successful : the reclaimed areas can be pointed out with pride ; the old 'hungry season' of MarchApril seems to have disappeared. Yet rice imports are increasing. Can it be that as new areas are reclaimed, equally large areas of upland are being abandoned ? Unfortunately, there are no map records, and we see here the inadequacy of statistics where a complete shift in cultivation from one part of an administrative unit to another would not appear at all in any statistics of land use. There could, indeed, be no clearer demonstration of the complementary character of cartographic and statistical-economic interpretation of data, or the inadequacy of the latter without the former.

The work in the Gambia has been carried out under the direction of Mr. Martin Brunt, land use officer of the Directorate of Overseas Surveys, working on air photographs coupled with three periods on the ground for vital checking. He used series of photographs taken in 1946 by the Royal Air Force and another series taken in 1956 by Aircraft Operating Co. (Aerial Surveys), Ltd. The fully coloured maps are able to show, therefore, the extension or retraction of rice lands.

It is characteristic of tropical agriculture that the intricate pattern of land use is apt to defeat the cartographer even on large scales. Gambia is no exception. In the two published sheets out of the projected thirty-five sheets for the central Gambia, six colours are devoted to cropland, three being for rice according to the proportion of the land cultivated-the actual plots are too small. The tidal flats show a complex mixture of high and low mangrove and grass marshes with a little 'barren marsh'. On high ground a distinction is made simply between 'woodland', 'fallow bush' and grass.

In due course an explanatory memoir is promised -no conclusions are drawn at this stage. In the meantime, there can be nothing but praise and admiration for all concerned: a far-sighted Govern- ment for commissioning a survey and the publication of a factual document in the form of maps which cannot fail to be of permanent value for all time; a technically excellent publication; and a land use officer who understands clearly the problems involved.

A somewhat similar problem in a still more acute form is presented by the island of Singapore. More than a million and a half people are crowded into an area the size of the Isle of Man. The urgent questions are largely those of town planning, but there are patches of land excellent for intensive market gardening, producing much-needed fresh vegetables for the local market; there are light lands with excellent coconut groves; and, though pineapples have been ousted and rubber is being squeezed out, poor soils remain in second growth scrub protecting water supplies. There are swamp lands inviting reclamation, and once again a careful record and understanding are vital. In this case the mapping is being carried out by the University of Malaya. The survey tradition established in the Department of Geography by Prof. E. H. G. Dobby (now of Ghana) is being ably continued by Robert Ho, Paul Wheatley and their team, and the first sheet* out of ninety-four projected on the scale $l: 6,336$ ( 10 in. to the mile) has just been published for the Singapore Improvement Trust. Some twenty categories of rural land use are shown, and in addition urban land uses are fully delineated. Like the map of the Gambia, this constitutes a factual document of utmost and lasting value. By showing things as they are and then in the explanatory memoir which is in preparation attempting an explanation, we are led away from that dangerous short cut of mapping 'land capability classes' decided so frequently on inadequate knowledge and based inevitably on a subjective judgment with presentday conditions in mind.

L. Dudley Stamp

* Singapore Land Use Map, Sheet S/49. Singapore Improvement Trust. 1:6,336. Field work by Geography Dept., University of Malaya, July 1958 .

\section{EUROPEAN ORGANIZATION FOR NUCLEAR RESEARCH}

\section{REPORT FOR 1957}

$\mathrm{T}$ HE third annual report of the European Organization for Nuclear Research* (CERN) covers the period to the end of 1957 and includes a list of the twelve member States of the Organization; their percentage contributions to the budgets for the years 1957, 1958 and 1959; details of the structure and membership of the council; and a list of the names of the senior staff of the Organization.

During the period under review, the constructional work on both the proton synchrotron and the synchrocyclotron accelerators and the buildings on the Meyrin site has progressed according to schedule. The $600-\mathrm{MeV}$. synchro-cyclotron came into operation on August 1, 1957, and already an interesting programme of research under the supervision of Prof. M. Bernardini, the research director of the Synchro-cyclotron Division, has commenced. Details of the construction and testing of the accelerator are given in a separate section of the report. They include the investigation of properties of the internal proton beam; the installation of the several beam-bending magnets; the construction of the final shielding wall to give protection against neutrons; and the fitting of appropriate channels for mesons and neutrons. The Proton-synchrotron Division has passed the design, planning and ordering stage, and has entered upon the active phase of the construction of the machine and of its ancillary equipment. The whole Division, consisting of 165 staff members engaged on the design and construction of the synchrotron and nine Fellows in the research group studying new ways of accelerating particles, is now installed at Meyrin, and the old offices and laboratories at the Institute of Physics in Geneva have been vacated. The first scheme to be studied by the research group was the plasma ring accelerator proposed by Budker at the CERN Symposium in 1956. Both theoretical studies and experimental studies with an air-cored betatron have been carried out. It is expected that the experiments will indicate the general utility of plasma ring discharges as accelerator guide fields.

The offices, laboratories, experimental halls and the ring complex are all finished and occupied by 